\title{
Statistical analysis of low molecular mass heparin nanoencapsulation
}

\author{
VAISHNAVI GANTI ${ }^{1}$ \\ ABEBE ENDALE MENGESHA ${ }^{1}$ \\ JACOB MARSZALEK ${ }^{2}$ \\ BI-BOTTI C. YOUAN ${ }^{1, *}$ \\ ${ }^{1}$ Laboratory of Future Nanomedicines \\ and Theoretical Chronopharmaceutics \\ University of Missouri-Kansas City \\ School of Pharmacy \\ Division of Pharmaceutical Sciences \\ Kansas City MO 64108 \\ 2 University of Missouri-Kansas City \\ School of Education, Division of \\ Counseling E Education Psychology \\ Kansas City, MO 64110
}

\begin{abstract}
The objective of this study was to use Box-Behnken design (BBD) to investigate the influence of formulation variables on the properties of heparin-loaded poly(lactic-co-glycolic acid) (PLGA)-polymethacrylate-RLPO (E-RLPO) nanoparticles (NP) in terms of mean diameter (as size) and drug encapsulation efficiency. The NPs were prepared by the double emulsion solvent evaporation method. The independent variables were: $X_{1}$ - polymer mass ratio (PLGA:E-RLPO) in the oil phase, $X_{2}$ - concentration of polyvinyl alcohol (PVA) as emulsion stabilizer, and $X_{3}$ - volume of the external aqueous phase $\left(W_{2}\right)$. Particle size (analyzed by dynamic light scattering) and encapsulation efficiency ( $E E$, estimated by spectrophotometry) were the investigated responses. The polynomial equation obtained from regression analysis of the reduced model $\left(p=0.0002, F=25.7952\right.$ and $\left.R^{2}=0.96\right)$ provided an excellent fit. The optimal size for the NP was found to be $134.2 \pm 16.5 \mathrm{~nm}$ with formulation variables of 48.2:61.8, $0.321(\%, m / V)$ and $263 \mathrm{~mL}$ for $X_{1}, X_{2}$ and $X_{3}$, respectively. Probably, due to electrostatic interaction between the negatively charged drug and the positively charged E-RLPO, the percent $E E$ of heparin was between $74.4 \pm 6.5 \%$ (lowest value) and $92.1 \pm 5.3 \%$ (highest value). The data suggest that BBD is a useful tool in rational design of heparin-loaded NPs.
\end{abstract}

Keywords: heparin, nanoparticle, encapsulation efficiency, Box-Behnken design

The concept of quality by design in the pharmaceutical field requires better control of drug formulation and manufacturing processes (1) to ensure robust and predictable outcomes. To circumvent these limitations, there is emerging interest in using mathematical methods to better predict drug formulations (2). To contribute to this knowledge gap in the field, specifically for drug nanoencapsulation, this study reports on the application of statistical analysis to elucidate the features of heparin-loaded nanoparticles.

\footnotetext{
* Correspondence; e-mail: youanb@umkc.edu
} 
Heparin is a water soluble, negatively charged molecule belonging to the group of glycoso-aminoglycans. Its anticoagulant action is well established (3). After injection, heparin chains enter a cellular pool and effectively prevent thrombosis by increasing the electronegative potential of the vessel wall (4). Low-molecular-mass heparins (LMWH's) are heparin salts having an average molecular mass of less than $8000 \mathrm{Da}$. Heparin is still essentially administered in clinics by injections, which presents several limitations for effective pharmacotherapy of thrombosis. To overcome these limitations, a non-invasive and improved heparin delivery system may be needed to enhance patient compliance and minimize adverse effects (5). Alternative for heparin delivery, which are under research include the pulmonary route (6) that offers many advantages. Considering the above aspects and the urgent need for an alternative route for heparin, the long-term goal of this research endeavour is to formulate heparin-loaded nanoparticles for pulmonary delivery. In pursuit of that goal, the immediate objective of this study was to optimize heparin nanoencapsulation with a polymeric matrix using the double-emulsion solvent-evaporation method.

A 3-factor, 3-level Box-Behnken design (BBD) was employed to design experiments based on the response surface methodology (7). The design specified low, medium, and high values for the chosen variables. BBD is an efficient experimental design method, because it involves fewer experiments compared to a full factorial design. In this study, the influence of independent variables, such as polymer ratio, stabilizer concentration and volume of the external phase, on the particle size and encapsulation efficiency was analyzed.

\section{EXPERIMENTAL}

\section{Materials}

Polymethacrylate Eudragit ${ }^{\mathrm{TM}}$ or Eudragit $\mathrm{C}$ RLPO (E-RLPO) was purchased from Röhm Pharma GmbH (Germany). Poly(DL-lactide-co-glycolide) (PLGA) with inherent viscosity $\left(\eta_{\text {inh }}=\ln \eta_{\text {rel }} / \mathrm{c}\right.$, natural logarithm of the ratio between relative viscosity, $\eta_{\text {rel }}$ and polymeric dispersion concentration, $c$ of $1.08 \mathrm{dL} \mathrm{g}^{-1}$ at $30{ }^{\circ} \mathrm{C}$ and a lactide-to-glycolide ratio of 50:50 was obtained from Birmingham Polymers, Inc. (USA). Polyvinyl alcohol (PVA) $\left(M_{\mathrm{r}} 30-70 \mathrm{kDa}\right)$ and Azure-II dye were purchased from Sigma (USA). Methylene chloride (Fischer Scientific, USA), low-molecular-mass heparin (LMWH, lot \# PH $61807 @ 170$ IU mg-1) (Celsus, USA), and all other chemicals were of analytical grade and were used without further purification.

\section{Experimental design}

The experimental design and analysis of the results were performed using the JMP version 5.1 software (SAS Institute, USA). The 3-factor, 3-level BBD was used to optimize the particle size and percent encapsulation of the drug. The number of experiments $(N)$ required was determined using the following equation (7):

$$
N=(2 k)(k-1)+C_{0}
$$


where $k$ is the number of factors and $C_{0}$ is the number of central points. In this study, three factors $(k=3)$ and three central points $\left(C_{0}=3\right)$ were considered, providing a total of 15 experiments according to Eq. (1). The independent variables are defined in Table I. Based on the analysis of the data and the model obtained after multiple regression, a polynomial equation was predicted defining the optimized nanoparticles in terms of the least diameter size (after freeze drying) and maximum heparin encapsulation.

Table I. Independent variables and their levels in Box-Behnken design

\begin{tabular}{lccc}
\hline \multirow{2}{*}{ Independent variable } & \multicolumn{3}{c}{ Level } \\
\cline { 2 - 4 } & Low & Medium & High \\
\hline Polymer ratio (PLGA:E-RLPO) & $20: 80$ & $50: 50$ & $80: 20$ \\
PVA $(\%, m / V)$ & 0.1 & 0.3 & 0.5 \\
External phase volume $(\mathrm{mL})$ & 100 & 200 & 300 \\
\hline
\end{tabular}

\section{Preparation of heparin-loaded nanoparticles}

LMWH-loaded nanoparticles were prepared by an adapted multiple emulsion $(\mathrm{w} / \mathrm{o} / \mathrm{w})$ technique (8). In this, $1 \mathrm{~mL}$ of an aqueous heparin solution (5000 IU) was first emulsified in methylene chloride $(10 \mathrm{~mL})$ containing $0.5 \mathrm{~g}$ of the polymers by sonication (VWR, USA) for $1 \mathrm{~min}$ at $60 \mathrm{~W}$. The resulting water-in-oil (w/o) emulsion was poured into an aqueous solution containing PVA, and mixed in a homogenizer (Ultra Turrax, T-25 basic, USA) for $3 \mathrm{~min}$. This formed the secondary water-in-oil-in-water $(\mathrm{w} / \mathrm{o} / \mathrm{w})$ emulsion. The organic solvent was removed at room temperature $\left(32-37^{\circ} \mathrm{C}\right)$ with continuous magnetic stirring for 2 hours. The emulsion was centrifuged at 20,000 rpm (29, $100 \mathrm{xg}$ ) for $60 \mathrm{~min}$, washed three times with water to remove excess PVA, and then dried in a freeze-dryer (Labconco Co., USA). Samples were taken for particle size analysis before and after the freeze-drying. The supernatant collected after centrifugation was analyzed for heparin, and the encapsulation efficiency $(E E)$ was calculated.

\section{Characterization of nanoparticles}

Particle size. - Particle size was measured by differential light scattering (DLS) (Brookhaven Instruments Corp., USA) with the 90 Plus particle-sizing software (version 3.78). Typically, 1-2 mL of the appropriately diluted sample was measured in triplicate. In order to evaluate the effect of the drying process on the NP, samples were measured before and after the freeze-drying.

Morphology analysis. - Surface features of the NP were analyzed using scanning electron microscopy (SEM) (FEI Co., USA). Samples of NP were fixed on supports with carbon-glue, and coated with gold-palladium under an argon atmosphere using a gold sputter module in a high-vacuum evaporator. The morphology of the samples was observed with XL-30, ESEM-FEG (FEI Co.). 
Determination of drug encapsulation efficiency. - The supernatant recovered by centrifugation during washing of the NPs was assayed using spectrophotometry (Genesys 10 Bio, Thermo Electron Co., USA) after appropriate dilution (9). A standard curve was first plotted with heparin in the concentration range 1-5 IU mL-1. Typically, an aliquot of 0.5 $\mathrm{mL}$ of aqueous heparin solution, or the supernatant from NP preparation, was reacted with $4.5 \mathrm{~mL}$ of Azure II solution $\left(0.01 \mathrm{mg} \mathrm{mL}^{-1}\right)$ at room temperature and assayed at $530 \mathrm{~nm}$. Experiments were conducted in triplicate. Mean values and standard deviations were calculated for each sample. Heparin concentration (IU mL $\mathrm{mL}^{-1}$ ) was determined from the standard curve using values for the slope and intercept $\left(0.0185 \mathrm{~mL} \mathrm{IU}^{-1}\right.$ and 0.0057 , respectively, $R=0.9939$ ). The drug entrapment efficiency was expressed as the percentage of heparin entrapped compared to the theoretical value.

\section{RESULTS AND DISCUSSION}

\section{Particle size analysis}

Heparin-loaded nanoparticles ranging from 150-875 nm were prepared after freeze-drying (Table II) using the 15-set of experiments of the BBD. As shown in Table II, the

Table II. Experimental design with measured responses

\begin{tabular}{cccccccc}
\hline $\begin{array}{c}\text { Batch } \\
\text { No. }\end{array}$ & Pattern ${ }^{\mathrm{a}}$ & $\begin{array}{c}\text { Polymer } \\
\text { ratio }(\%)\end{array}$ & $\begin{array}{c}\text { PVA } \\
(\%, m / V)\end{array}$ & $\begin{array}{c}\text { External Diameter be- } \\
\text { phase } \\
(\mathrm{mL})^{\mathrm{b}}\end{array}$ & $\begin{array}{c}\text { Dore freeze- } \\
\text {-drying }(\mathrm{nm})\end{array}$ & $\begin{array}{c}\text { Diameter after } \\
\text { freeze-drying }\end{array}$ & $\begin{array}{c}\text { Encapsulation } \\
\text { efficiency }^{\mathrm{c}} \\
(\%)\end{array}$ \\
\hline 1 & $0+-$ & $50: 50$ & 0.5 & 100 & 221.1 & $391.3 \pm 33.9$ & $82.5 \pm 1.6$ \\
2 & $+0-$ & $80: 20$ & 0.3 & 100 & 334.7 & $589.2 \pm 50.9$ & $75.1 \pm 8.9$ \\
3 & ++0 & $80: 20$ & 0.5 & 200 & 446.0 & $346.5 \pm 21.2$ & $74.4 \pm 6.5$ \\
4 & $-0+$ & $20: 80$ & 0.3 & 300 & 190.1 & $194.8 \pm 65.1$ & $87.3 \pm 7.5$ \\
5 & 000 & $50: 50$ & 0.3 & 200 & 277.3 & $211.5 \pm 35.4$ & $87.7 \pm 5.7$ \\
6 & $0--$ & $50: 50$ & 0.1 & 100 & 743.4 & $875.7 \pm 91.9$ & $89.4 \pm 6.6$ \\
7 & --0 & $20: 80$ & 0.1 & 200 & 373.4 & $602.1 \pm 53.7$ & $92.1 \pm 5.3$ \\
8 & $0++$ & $50: 50$ & 0.5 & 300 & 469.1 & $301.2 \pm 33.9$ & $81.1 \pm 7.9$ \\
9 & -+0 & $20: 80$ & 0.5 & 200 & 196.9 & $150.4 \pm 17.0$ & $91.1 \pm 4.1$ \\
10 & +-0 & $80: 20$ & 0.1 & 200 & 271.4 & $348.5 \pm 45.3$ & $77.9 \pm 8.3$ \\
11 & $0-+$ & $50: 50$ & 0.1 & 300 & 344.5 & $252.4 \pm 53.7$ & $87.5 \pm 9.5$ \\
12 & 000 & $50: 50$ & 0.3 & 200 & 209.2 & $165.0 \pm 22.6$ & $88.5 \pm 6.7$ \\
13 & $+0+$ & $80: 20$ & 0.3 & 300 & 235.6 & $210.4 \pm 19.8$ & $90.1 \pm 0.1$ \\
14 & $-0-$ & $20: 80$ & 0.3 & 100 & 286.8 & $416.0 \pm 41.0$ & $80.1 \pm 6.8$ \\
15 & 000 & $50: 50$ & 0.3 & 200 & 224.1 & $213.6 \pm 14.1$ & $82.5 \pm 5.8$ \\
\hline
\end{tabular}

a Pattern: (-) low, (0) medium, (+) high (Table I).

${ }^{b}$ Volume of the external water phase in the $\mathrm{w} / \mathrm{o} / \mathrm{w}$ emulsion.

c Diameter and EE are mean values $\pm \operatorname{SD}(n=3)$. 
low levels of PVA and external aqueous phase volume (Table I) resulted in large heparin-loaded particles with a mean diameter of $875 \pm 92 \mathrm{~nm}$. On the other hand, the high level of PVA $(0.5 \%, m / V)$, medium level of external phase volume $(200 \mathrm{~mL})$, and low level of PLGA:E-RLPO polymer ratio (20:80) provided the smallest particle size (150 $\pm 17 \mathrm{~nm})$. These factors, affecting the size range of the NPs, are discussed in detail in the sections below.

\section{Morphological analysis}

Surface morphology studies of the heparin-loaded nanoparticles of the different sets of BBD batches showed variation in size consistent with the results in Table II. Figs. 1a and $1 \mathrm{~b}$ show typical SEM pictures of the small- and large-sized nanoparticles produced by BBD experiments in batches 9 and 6, respectively.

In some of the SEM pictures, the remnants of PVA are clearly visible in the form of a mesh-like structure. Repeated washings have removed most of the PVA from the NPs. Fig. 1c shows typical PVA-containing NPs before the washing steps. Heparin-loaded NPs are not clearly visible under the SEM due to the PVA covering layers. Indeed, it has been shown that some amount of the PVA is always found to be associated with polymer nanoparticles, even after repeated washings (10). After washing, the heparin-loaded NPs appeared to be smooth, spherical and nonporous in both isolated and aggregated forms (Fig. 1).

a)

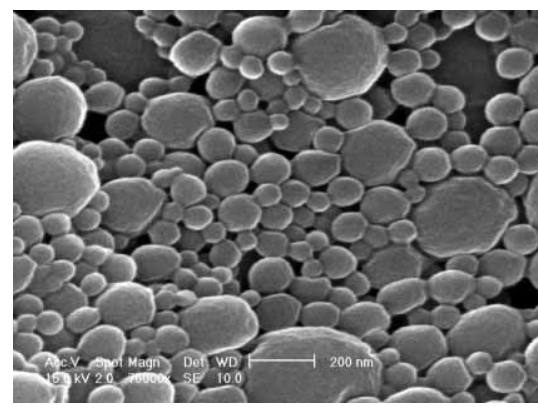

c)

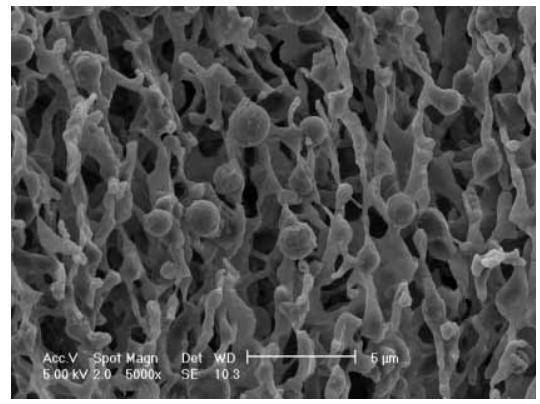

b)

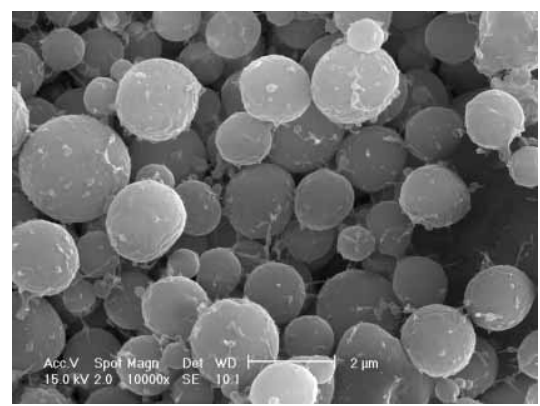

Fig. 1. SEM of heparin-loaded nanoparticles: a) small-sized nanoparticles (batch No. 9, Table II), b) large-sized nanoparticles (batch No. 6, Table II), c) heparin-loaded nanoparticles before washing out PVA. 


\section{Drug encapsulation analysis}

The drug encapsulation efficiency $(E E)$ of the nanoparticles was remarkably high, ranging from $74.4 \pm 8.9 \%$ (batch No. 3) to $92.1 \pm 5.3 \%$ (batch No. 7) (Table II). This also suggests that the system in the present experimental setup was robust with respect to the percentage of drug encapsulated. The narrow range over which the $E E$ varied for the system was mainly due to incorporation of the positively charged E-RLPO, which took part in an electrostatic interaction with the negatively charged heparin macromolecules (11).

\section{Analysis of experimental data}

Data obtained for the size and encapsulation efficiency based on the fifteen BBD experiments (Table II) were analyzed as shown in Figs. 2-4 by depicting Pareto plots and contour profiles, and examining the regression model parameter estimates residual
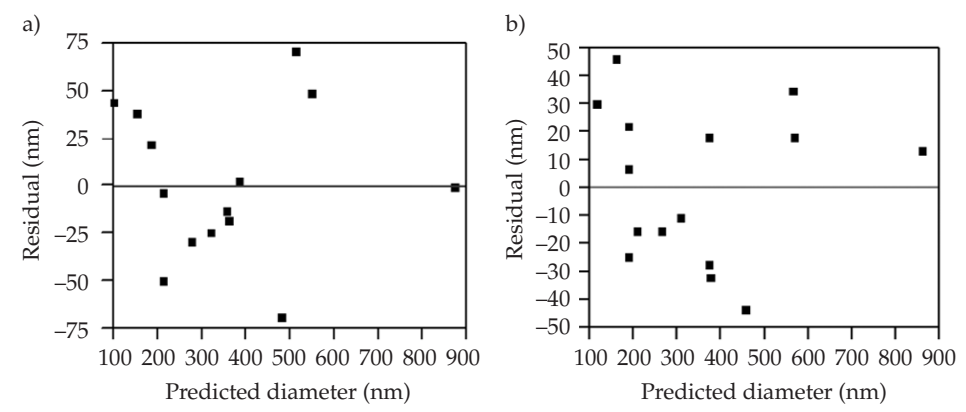

Fig. 2. Residuals vs. predicted particle size of the heparin-loaded nanoparticles:

a) full model, b) reduced model.

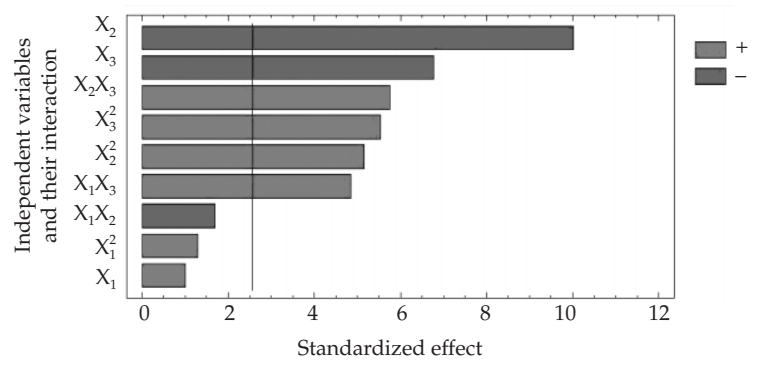

Fig. 3. Standardized Pareto chart for the particle size of heparin-loaded nanoparticles after freeze-drying. Independent variables: $X_{1}$ - polymer mass ratio (PLGA: E-RLPO) in the oil phase; $X_{2}$ - concentration of polyvinyl alcohol (PVA $\%, m / V$ ) as emulsion stabilizer; and $X_{3}$ - volume of the external aqueous phase $(\mathrm{mL})$ and their corresponding interaction. Statistical significance level $(p=$ $0.05)$ is indicated by the vertical line. 
Fig. 4. Contour plot of the particle size (nm) as the function of external phase volume and PVA concentration. Polymer ratio was kept constant at the center point.

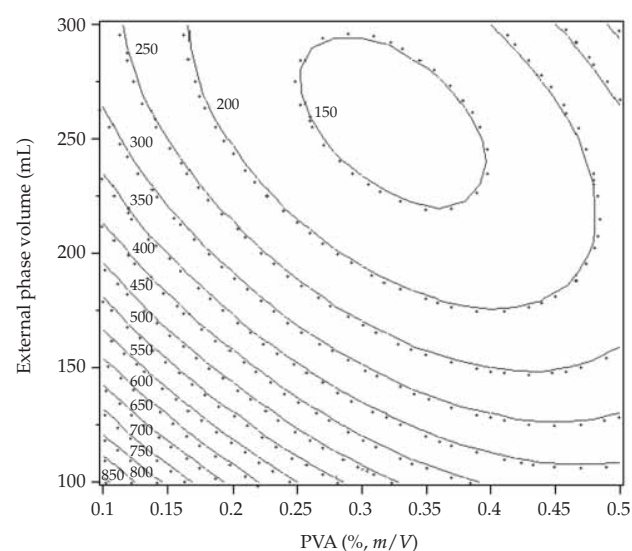

plots. Except for batches 1, 2, 7 and 14, there was a good correlation between the size of heparin-loaded NPs before and after freeze-drying (Table II), suggesting that there was no need to use cryoprotectants for this type of nanoparticles. Abdelwahed et al. (12) described the stabilization of nanocapsule reservoir systems using $5 \%$ PVA as a cryoprotectant. In this study, the concentration of PVA in the heparin-loaded NP was usually less than $0.5 \%$. The reasons why these four samples exhibited dramatic increases in size during freeze-drying remain to be elucidated.

The encapsulation efficiency of the NPs was above $75 \%$ (Table II), which is considered acceptable for all levels of independent variables (Table I). Hence, the variables were optimized for particle size as described below.

Multiple regression analysis was performed using particle size as the response variable and polymer ratio (PLGA: E-RLPO), concentration of PVA $(\%, m / V)$, and volume of the external aqueous phase as independent variables. A polynomial equation determining the nanoparticle size was obtained based on the regression analysis, resulting in a model that predicted the size of heparin-loaded nanoparticles. Eq. (2) incorporates individual as well as combined effects of the independent variables:

$$
\begin{aligned}
Y=191.1 & +16.4 X_{1}-111.2 X_{2}-164.2 X_{3}+112.4 X_{1} X_{2}-39.4 X_{1} X_{3}+ \\
& +133.3 X_{2} X_{3}+34.2 X_{1}^{2}+136.7 X_{2}^{2}+127.4 X_{3}^{2}
\end{aligned}
$$

where, $Y$ is the partical size, $X_{1}$ is the percentage polymer ratio, $X_{2}$ is the concentration of PVA $(\%, m / V)$, and $X_{3}$ is the volume of the external aqueous phase (mL) (Table I). It is important to underscore that in this study, the total amount/mass of polymer used to form the NP matrix is constant. Only the relative proportion of PLGA to E-RLPO is the variable in this context. In this constant amount of polymer mixture, defining the mass or mass percentage of one polymer will automatically set the value for the second polymer. This reduces the percentage polymer ratio into a single factor. For example, a percentage ratio of 50:50 means that the polymeric portion contains by mass $50 \%$ of each type of polymer and indeed corresponds to a standard ratio of 1:1. From the regression 
V. Ganti et al.: Statistical analysis of low molecular mass heparin nanoencapsulation, Acta Pharm. 60 (2010) $281-293$.

Table III. Measured and calculated values for particle mean diameter after freeze-drying

\begin{tabular}{ccccc}
\hline $\begin{array}{c}\text { Batch } \\
\text { No. }\end{array}$ & $\begin{array}{c}\text { Observed } \\
\text { diameter }(\mathrm{nm})^{\mathrm{a}}\end{array}$ & $\begin{array}{c}\text { Predicted } \\
\text { diameter }(\mathrm{nm})\end{array}$ & $\begin{array}{c}\text { Residual } \\
(\mathrm{nm})^{\mathrm{b}}\end{array}$ & $\begin{array}{c}\text { Standard error } \\
(\mathrm{nm})^{\mathrm{c}}\end{array}$ \\
\hline 1 & $391.3 \pm 33.9$ & 374.8 & +16.5 & 23.9 \\
2 & $589.2 \pm 50.9$ & 572.5 & +16.7 & 35.8 \\
3 & $346.5 \pm 21.2$ & 379.5 & -33.0 & 15.0 \\
4 & $194.8 \pm 65.1$ & 211.4 & -16.6 & 45.9 \\
5 & $211.5 \pm 35.4$ & 196.7 & +14.8 & 25.1 \\
6 & $875.7 \pm 91.9$ & 863.7 & +12.0 & 64.8 \\
7 & $602.1 \pm 53.7$ & 569.0 & +33.1 & 37.9 \\
8 & $301.2 \pm 33.9$ & 313.1 & -11.9 & 23.0 \\
9 & $150.4 \pm 17.0$ & 121.8 & +28.6 & 12.1 \\
10 & $348.5 \pm 45.3$ & 377.0 & -28.5 & 31.8 \\
11 & $252.4 \pm 53.7$ & 268.8 & -16.4 & 37.9 \\
12 & $165.0 \pm 22.6$ & 196.7 & -31.7 & 15.9 \\
13 & $210.4 \pm 19.8$ & 165.4 & +45.0 & 14.1 \\
14 & $416.0 \pm 41.0$ & 460.9 & -44.9 & 29.3 \\
15 & $213.6 \pm 14.1$ & 196.7 & +16.9 & 9.9 \\
\hline
\end{tabular}

a Mean $\pm \mathrm{SD}, n=3$.

$\mathrm{b}$ Residual: observed diameter $(\mathrm{nm})$ - predicted diameter $(\mathrm{nm})$

analysis, the predicted values, residuals and standard errors for particle size were calculated and are shown in Table III. The $R^{2}$ value for the model was found to be 0.98 , indicating an excellent fit to the data. Nevertheless, analysis of the data showed that the coefficients of interactions, namely polymer ratio $x$ polymer ratio $\left(X_{1}^{2}\right)$, and polymer ratio $x$ external volume $\left(X_{1} X_{3}\right)$, were not statistically significant. Therefore, these interaction terms were omitted from the final model. This omission was justified by performing the following three different analyses:

(i) Regression analysis of the reduced model was performed and the $p$ (0.0002), F (25.7952) and $R^{2}(0.96)$ values (Table IV) verified an excellent fit. The above values were highly significant, justifying the omission of insignificant parameters.

(ii) Plot of residual vs. predicted values showed no correlation of data for either full (Fig. 2a) or reduced models (Fig. 2b).

(iii) Regression analysis for the residuals obtained in both full and reduced models was performed to justify the omission of insignificant interaction terms for obtaining a reduced polynomial equation.

The above tests justified the omission of insignificant parameters. The reduced polynomial equation was derived as shown below:

$$
\begin{gathered}
Y=212.1+16.4 X_{1}-111.2 X_{2}-164.2 X_{3}+112.4 X_{1} X_{2}+133.3 X_{2} X_{3}+ \\
+134.1 X_{2}^{2}+124.8 X_{3}^{2}
\end{gathered}
$$


where $Y$ is the praticle size, $X_{1}, X_{2}$ and $X_{3}$ are the same variables as defined above. The $R^{2}$ value for Eq. (3) was 0.96, which shows excellent fit, and the fit of the reduced model was not significantly different from that of the initial model as shown in Table IV by calculated $F\left(F_{\mathrm{CAL}}(5,7)=2.46, p=0.14\right)$. This table also indicates that the data fits to the reduced model as well. $C_{1}$ is the sum of squares of the residuals (error) of the full model; $C_{2}$ is the sum of squares of the residuals (error) of the reduced model, $D_{1}$ is the mean square of the error of the full model, $N_{\mathrm{TO}}$ is the number of terms omitted (which is 2 ). On closer analysis, it appears that both the concentration of PVA $(\%, m / V)\left(X_{2}\right)$ and the external phase volume $\left(X_{3}\right)$ have a quadratic effect on particle size when other variables are held constant, where particle size is minimized at the medium level of each. In addition, PVA concentration has a moderating effect on the relationship between the polymer ratio and particle size, where the high level of concentration adds $112.4 \mathrm{~nm}$ to the effect of polymer ratio, and the low level subtracts $112.4 \mathrm{~nm}$, when the volume of the external phase is held constant. Concentration of PVA also had a moderating effect on the relationship between the volume of the external phase and particle size, where the high level of concentration adds $133.3 \mathrm{~nm}$ to the effect of the external phase on particle size, and the low level subtracts $133.3 \mathrm{~nm}$ when the polymer ratio is held constant.

Pareto plots. - Pareto plots (Fig. 3) show the particle size varying curvilinearly with the volume of the external phase $\left(X_{3}\right)$ and the PVA concentration, the emulsifier $\left(X_{2}\right)$ indicating that at extremely low and extremely high values of these independent variables, it is possible to achieve maximum values for the response. Since the response under consideration is particle size, we should aim at medium values to obtain the smallest particle size, which is the ultimate objective of this work.

Contour profile. - To further elucidate the results from the Pareto plots, the contour profiles $X_{2}$ vs. $X_{3}$ were plotted (Fig. 4). The contour profile predicted the particle size of the heparin-loaded NPs to curvilinearly change with the two factors, PVA concentration and the volume of the external phase. The third factor, the polymer ratio, was kept constant at the medium value. As shown in Fig. 4, the smallest size of heparin-loaded NPs

Table IV. Results of ANOVA for the full model and reduced models predicting particle size

\begin{tabular}{|c|c|c|c|c|c|c|c|}
\hline Source & d.f. & $\begin{array}{l}\text { Sum of } \\
\text { squares }\end{array}$ & & $\begin{array}{l}\text { Mean } \\
\text { square }\end{array}$ & & $F$-value & $p$-value ${ }^{\mathrm{a}}$ \\
\hline \multicolumn{8}{|l|}{ Reduced model } \\
\hline Model & 7 & 530508.16 & & 75786.9 & & 25.7952 & 0.0002 \\
\hline Error & 7 & 20566.15 & $(\mathrm{C} 2)$ & 2938.0 & & & \\
\hline Corrected total & 14 & 551074.32 & & & & & \\
\hline \multicolumn{8}{|l|}{ Full model } \\
\hline Model & 9 & 565078.15 & & 62786.5 & & 30.3021 & 0.0009 \\
\hline Error & 5 & 10360.08 & (C1) & 2072.0 & (D1) & & \\
\hline Corrected total & 14 & 575438.24 & & & & & \\
\hline
\end{tabular}

a Probability of obtaining $F$-value greater than calculated.

$F_{\mathrm{CAL}}=\left[\left(C_{2}-C_{1}\right) / N_{\mathrm{TO}}\right] / D_{1}=2.46\left(\mathrm{df}_{1}=5, \mathrm{df}_{2}=7, p=0.14\right)$, where $N_{\mathrm{TO}}$ is the number of terms omitted. 
$(150 \mathrm{~nm})$ was obtained with PVA concentration in the range of $0.25-0.4 \%,(\mathrm{~m} / \mathrm{V})$, and the external phase volume varying from $225-290 \mathrm{~mL}$. Considering all the above observations, we concluded that the best values for obtaining the smallest particle size would be around the medium value of the PVA concentration and in-between the medium to high levels of the external phase (Fig. 4).

Prediction profiler. - The prediction profiler (Fig. 5) further confirmed the above observations. Fig. 5 displays prediction traces for each independent variable. A prediction trace is the predicted response obtained when one variable changes while the others are held constant at current values. Prediction profiles are especially useful in multiple-response models to help evaluate the factors helpful in optimizing an experimental design. Fig. 5 shows that it is possible to achieve the optimum size of $134.24 \mathrm{~nm}$ and encapsulation efficiency $(E E)$ of $88.8 \%$, with desirability of 0.95 on the scale of 0 to 1 , where 0 is not acceptable and 1 is the desirable response. Optimized independent variables were 48.2:61.8, $0.321(\%, m / V)$ and $263 \mathrm{~mL}$ for $X_{1}, X_{2}$ and $X_{3}$, respectively. Checkpoint analysis with this optimal condition analysis gave a mean size of $144.4 \pm 16 \mathrm{~nm}(n=3)$ and a mean residual of $10.16 \mathrm{~nm}$ with $90.1 \%$ EE. The size range of the optimal formula was similar to that of sample No. 9 of the BBD design, as shown by the dynamic light scattering data in Table II and morphologically in Fig. 1a.

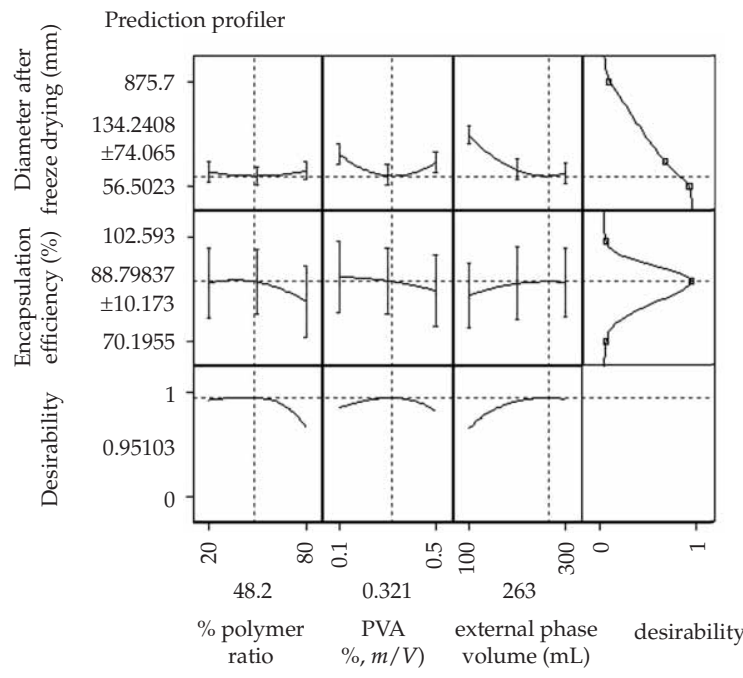

Fig. 5. Prediction and desirability plot of the reduced model showing the effect of polymer ratio $\left(X_{1}\right)$, concentration PVA $\left(X_{2}\right)$ and volume of the external phase $\left(X_{3}\right)$ on the particle size of heparin-loaded nanoparticles.

Physical meaning of statistical analysis. - The Pareto plot analysis, regression models, contour profiles and the prediction profiler gave predictable results about the effects on the responses due to individual and combined factors. From the Pareto plot, we deduced the nature of the relationship between the responses and the individual factors, which are significant. The particle size varies curvilinearly with PVA $(\%, m / V)$ and external phase volume, so the medium value of the parameter would give the desired re- 
sponse. Eq. (2) and Pareto plot (Fig. 3) showed that the influence of the polymer percentage ratio $\left(X_{1}\right)$ was not significant, either alone or when combined with the external phase volume $\left(X_{1} X_{3}\right)$. This may be explained by the fact that the various polymer ratios utilized in the study behaved in a similar way. The potential charge density effect, related to the different charges provided by the different levels of E-RLPO that were incorporated, might have been overridden by the steric effect of the PLGA.

Although polymer concentration is known to have an increasing effect on the diameter size, the levels of PVA concentration and external phase volume when used in combination, were found to minimize the effects on the particle size. Polymer concentration in the internal phase of the emulsion is an important factor due to its significant increasing effect on the particle size, but this effect was moderated by PVA concentration. This data may be explained by the fact that increasing viscosity of the dispersed phase leads to coarser dispersion of polymer solution into the aqueous phase (13). This could result from increased resistance due to the flow and shear stress during emulsification. Inadequate distribution of the phases during emulsification would produce an unstable emulsion, resulting in larger particle sizes and higher polydispersity (14).

In this study, PVA was used as an emulsion stabilizer. The amount of emulsion stabilizer plays an important role in the emulsification process and in the protection of droplets, because it can prevent coalescence of globules before particle hardening (14). The concentration of PVA clearly affects the particle size, although the effect partly depends on polymer ratio and external phase volume. At lower concentrations, the number of PVA macromolecules is not adequate to stabilize the emulsion. The resultant emulsion has coarser droplets and is more polydisperse. At higher PVA concentrations, the amount of residual PVA associated with the nanoparticles increased (13), leading to aggregation of the particles. This may be due to the interlocking of PVA and PLGA molecules during particle formation.

The external phase volume plays an important role in the formation and stability of the double emulsion system. With an increase in the external phase volume, the droplet size of the secondary emulsion decreases because of a decrease in the frequency of collision/coalescence of droplets, though the amount of decrease depends on the level of PVA concentration. This may also be explained by the Oswald ripening process (15), in which small particles shrink due to enhanced solubility arising from their high curvature while larger particles grow.

\section{CONCLUSIONS}

The statistical analysis based on BBD design provided the best data fit to the regression formula containing significant factor coefficients that predicted particle diameter values (after freeze-drying). The values of independent variables for the above predicted responses were 48.2:61.8 (PLGA:E-RLPO), 0.321 (PVA \%, $\mathrm{m} / \mathrm{V}$ ), $263 \mathrm{~mL}$ (external phase volume) and are in agreement with the results obtained from the contour profiler, checkpoint analysis and the Pareto plot.

The nanosystem was found to be robust with respect to the percentage of drug encapsulation. Future studies should also include the development of predictive mathe- 
matical models relating the influence of process parameters and other factors that may affect nanoparticle characteristics (e.g., size, drug encapsulation, and drug release and stability). Some of these process parameters and factors include the rate and speed of stirring, polymer molecular mass, internal/external phase ratio, operation temperature, and the method of solvent removal. In addition, it would be interesting to study the amount and type of residual emulsion stabilizers associated with nanoparticles, and their effect on the physico-chemical properties of the particles themselves.

\section{REFERENCES}

1. R. A. Lionberger, S. L. Lee, A. Raw and L. X. Yu, Quality by design: concepts for ANDAs, AAPS Journal 10 (2008) 268-276; DOI: 10.1208/s12248-008-9026-7.

2. L. C. Du Toit, V. Pillay, M. P. Danckwerts and C. Penny, Formulation and statistical optimization of a novel crosslinked polymeric anti-tuberculosis drug delivery system, J. Pharm. Sci. 97 (2008) 2176-2207; DOI: 10.1002/jps.21159.

3. P. S. Damus, M. Hicks and R. D. Rosenberg, Anticoagulant action of heparin, Nature 246 (1973) 355-357; DOI: 10.1038/246355a0.

4. L. B. Jacques, Heparin: an old drug with a new paradigm, Science 206 (1979) 528-533; DOI: 10. $1126 /$ science. 386509 .

5. M. Meysman and P. Haentjens, Pulmonary embolism: current treatment options, Curr. Treat. Options Cardiovas. Med. 7 (2005) 483-490; DOI: 10.1007/s11936-005-0034-y.

6. N. A. Motlekar and B. B. Youan, The quest for non-invasive delivery of bioactive macromolecules: a focus on heparins, J. Control. Rel. 113 (2006) 91-101; DOI: 10.1016/j.jconrel.2006.04.008.

7. G. E. P. Box and D. W. Behnken, Some new three level designs for the study of quantitative variables, Technometrics 2 (1960) 455-476; DOI: 10.2307/1266454.

8. A. Lamprecht, N. Ubrich, M. Hombreiro Perez, C. Lehr, M. Hoffman and P. Maincent, Influences of process parameters on nanoparticle preparation performed by a double emulsion pressure homogenization technique, Int. J. Pharm. 196 (2000) 177-182; DOI: 10.1016/S0378-5173(99) 00422-6.

9. L. H. Lam, J. E. Silbert and R. D. Rosenberg, The separation of active and inactive forms of heparin, Biochem. Biophys. Res. Commun. 69 (1976) 570-577; DOI: 10.1016/0006-291X(76)90558-1.

10. S. K. Sahoo, J. Panyam, S. Prabha and V. Labhasetwar, Residual polyvinyl alcohol associated with poly (D,L-lactide-co-glycolide) nanoparticles affects their physical properties and cellular uptake, J. Control. Rel. 82 (2002) 105-114; DOI: 10.1016/S0168-3659(02)00127-X.

11. Y. Jiao, N. Ubrich, M. Marchand-Arvier, C. Vigneron, M. Hoffman, T. Lecompte and P. Maincent, In vitro and in vivo evaluation of oral heparin-loaded polymeric nanoparticles in rabbits, Circulation 105 (2002) 230-235; DOI: 10.1161/hc0202.101988.

12. W. Abdelwahed, G. Degobert and H. Fessi, A pilot study of freeze drying of poly(epsilon-caprolactone) nanocapsules stabilized by poly(vinyl alcohol): formulation and process optimization, Int. J. Pharm. 309 (2006) 178-188; DOI: 10.1016/j.ijpharm.2005.10.003.

13. M. F. Zambaux, F. Bonneaux, R. Gref, P. Maincent, E. Dellacherie, M. J. Alonso, P. Labrude and C. Vigneron, Influence of experimental parameters on the characteristics of poly(lactic acid) nanoparticles prepared by a double emulsion method, J. Control. Rel. 50 (1998) 31-40; DOI: 10. 1016/S0168-3659(97)00106-5.

14. D. Quintanar-Guerrero, H. Fessi, E. Allemann and R. E. Doelke, Influence of stabilizing agents and preparative variables on the formation of poly(D,L-lactic acid) nanoparticles by an emul- 
sification-diffusion technique, Int. J. Pharm. 143 (1996) 133-141; DOI: 10.1016/S0378-5173(96) 04697-2.

15. Y. Liu, K. Kathan, W. Saad and R. K. Prud'homme, Ostwald ripening of beta-carotene nanoparticles, Phys. Rev. Lett. 98 (2007) 036102; DOI: 10.1103/PhysRevLett.98.036102.

\section{$S A \check{Z} E T A K$}

\section{Statistička analiza nanokapsuliranja niskomolekularnog heparina}

VAISHNAVI GANTI, ABEBE ENDALE MENGESHA, JACOB MARSZALEK i BI-BOTTI C. YOUAN

Box-Behnkenovo dizajniranje (BBD) primijenjeno je za praćenje utjecaja formulacijskih varijabli na svojstva nanočestica (NP) s heparinom. Za izradu nanočestica korišten je kopolimer mliječne i glikolne kiseline (PLGA) i polimetakrilat-RLPO (E-RLPO). Nanočestice su pripravljene metodom dvostruke evaporacije otapala iz emulzije. Nezavisne varijable bile su: $X_{1}$ - omjer masa polimera (PLGA : E-RLPO) u uljnoj fazi, $X_{2}$ - koncentracija polivinil alkohola (PVA) kao stabilizatora emulzije i $X_{3}$ - volumen vanjske vodene faze $\left(W_{2}\right)$. Zavisne varijable bile su veličina čestica (analizirana pomoću dinamičkog rasapa svjetlosti) i učinkovitost inkapsuliranja (EE) (praćena spektrofotometrijski). Polinomska jednadžba dobivena regresijskom analizom reduciranog modela odlično je odgovarala ( $p=0,0002, F=25,7952$ i $\left.R^{2}=0,96\right)$. Optimalna veličina nanočestica bila je $134,2 \pm$ $16,5 \mathrm{~nm}$ s formulacijskim varijablama $48,2: 61,8,0,321(\%, \mathrm{~m} / V)$ i $263 \mathrm{~mL}$ for $X_{1}, X_{2}$ odnosno $X_{3}$. Vjerojatno je zbog elektrostatskih interakcija između negativno nabijene ljekovite tvari i pozitivno nabijenog E-RLPO učinkovitost inkapsuliranja heparina varirala od $74,4 \pm 6,5 \%$ (najniža vrijednost) do $92,1 \pm 5,3 \%$ (najviša vrijednost). Rezultati sugeriraju da je BBD vrlo korisno $u$ racionalnom dizajniranju nanočestica s heparinom.

Ključne riječi: heparin, nanočestica, stupanj inkapsuliranja, Box-Behnkenovo dizajniranje

Laboratory of Future Nanomedicines and Theoretical Chronopharmaceutics, University of

Missouri-Kansas City, School of Pharmacy, Division of Pharmaceutical Sciences, Kansas City MO 64108

University of Missouri-Kansas City, School of Education, Division of Counseling E Education Psychology, 615 East 52nd Street, Kansas City, MO 64110 